\title{
Experiment Study on the Effects of Natural Zeolite on Sludge Dewatering Performance and Nitrogen Losses
}

\author{
Haibo Shi, Jianzhong Zhu* \\ Key Laboratory for Integrated Regulation and Resources Exploitation on Shallow Lakes, Ministry of Education, Hohai \\ University, Nanjing Jiangsu, 210098 China; College of Environment, Hohai University, Nanjing 210098, China \\ *Corresponding author: Jianzhong Zhu \\ E-mail address: zhuhhai2010@hhu.edu.cn
}

\author{
Jianbiao Chen \\ Nantong Hydrographic Office \\ Nantong China
}

\author{
Xudong Qiu \\ Nantong Water Conservancy Project Management \\ Nantong China
}

\begin{abstract}
Chemical conditioning pretreatment does not always improve sludge dewaterability sufficiently for flocculated sludges with high compressibilities. Physical conditioners, often knows as skeleton builders, are commonly used to improve the dewaterability of sewage sludge. In this study, natural zeolite was used as a skeleton builder, in combination with cationic polyacrylamide (CPAM) or ferric chloride. The filter ability of co-conditioned sludge was affected by the dose of the natural zeolite was evaluated using Specific Resistance to Filtration (SRF) as well as moisture content (MC). The results showed that pretreating the sludge with a combination of natural zeolite and CPAM or ferric chloride can improve sludge dewaterability over CPAM or ferric chloride conditioning alone. When used $2.5 \mathrm{~kg} /$ tonne CPAM and natural zeolite to adjust the sludge, the maximum reduction of the SRF is form $1.4294 \times 1013 \mathrm{~m} / \mathrm{kg}$ to $1.009 \times 1013 \mathrm{~m} / \mathrm{kg}$, and the maximum reduction of the moisture content (MC) is from $86.04 \%$ to 82.17\% . Experiments demonstrated that the natural zeolite (>140meshes) can reduce the concentration of ammonia nitrogen in the reject water, the maximum reduction of the concentration of ammonia nitrogen is from $7.079 \mathrm{mg} / \mathrm{L}$ to $2.921 \mathrm{mg} / \mathrm{L}$. So it can improve the mass of the nitrogen nutrient in sewage sludge after dehydration and improve agricultural potential of the sludge. Use $2.5 \%$ dry solid (DS) of ferric chloride in combination with the optimum partical size (>140meshes) to adjust the sludge, the maximumreduction of the $S R F$ is from $1.38 \times 1013 \mathrm{~m} / \mathrm{kg}$ to $1.09 \times 1013 \mathrm{~m} / \mathrm{kg}$.
\end{abstract}

Keywords-Sewage sludge; Dewatering; Natural zeolite; Skeleton builder; Nitrogen nutrient

\section{INTRODUCTION}

Wastewater treatment processes produce large amounts ofsludge that commonly contain over $95 \%$ water[1]. This high moisture content cause the high costs of transportation and handing. So the reduction of the sludge volum become the most important part of sludge treatment prior to disposal.

The presence of organic components, mainly bacterial cells and extracellular polymeric substances (EPSs), and supracolloidal $(>1 \mathrm{~lm})$ particles in the sewage sludge makes the dewatering difficult even at the high pressures of mechanical dewatering[2]. Chemical conditioners,such as polyacrylamide, inorganic flocculant, and surfactants has been used as a conditioner for improving sludge dewater ability. However, achieving final cake solids of a significantly higher solids concentration is hindered by the high compressibility of the flocculated sludge during the compression stage of mechanical dewatering and the sludge cake particles can be easily deformed under pressure following cake growth causing cake void closure and a subsequent reduction in sludge filter ability [1].

Physical conditioners, known as skeleton builders or filtration aids, have been employed to improve the dewaterability of sludge. These physical conditioners can form permeable and more rigid lattice structures that can remain porous during mechanical dewatering [3]. A wide range of carbon-based materials have been used as physical conditioners, including lignite [4], char [5], coal fines [6]. Organic waste solids such as bagasse[7], wood chips and wheat dregs[8]. Minerals including gypsum [9-11], fly ash from municipal sludge incineration [12], coal fly ash modified by sulfuric acid [13], cement kiln dust [14].

Natural zeolite has many functions as a non-matallic mineral material. It has apply in many fields, such as environmental engineering, agriculture [15], chemistry [16]. It has a strong adsorptive capacity so that it can be used as a adsorbent to disposal sewage, purify drinking water: removal of ammonia nitrogen and organics [17], removal of metal ions [18, 19] and air purification [20, 21].

Although inert materials have been previously investigated as sludge conditioners, natural zeolite has not been used as a skeleton builder to condition sludge. This study explored the improvement of municipal sludge dewater ability by co-conditioning with natural zeolite and CPAM; natural zeolite and ferric chloride; the different characteristics of this two methods are disscussed in this paper. The optimal partical size of natural zeolite in condition of sludge and reduction of the concentration of ammonia nitrogen in the reject water is also investigated. 


\section{MAterial AND Methods}

A.

Test Materials

The sludge samples were collected from a municipal sewage treatment plant in Nanjing City, China. To minimize microbial activity, the samples were stored in a refrigerator $\left(\right.$ at $\left.4^{\circ} \mathrm{C}\right)$. The sludge sample characteristics are shown in TABLE I.

TABLE I. CHARACTERISTICS OF THE RAW SLUDGE SAMPLE

\begin{tabular}{ccc}
\hline Parameters & Unit & Value \\
\hline PH & - & $6.58-6.72$ \\
$\begin{array}{c}\text { Moisture content } \\
\text { specific resistance }\end{array}$ & $\%$ & $96.06-97.40$ \\
to filtration $($ SRF) & $\mathrm{m} / \mathrm{kg}$ & $2.2468-2.2537 \times 1013$ \\
\hline
\end{tabular}

Natural zeolite was obtained from Shijiazhuang City, Hebei Province, China. Its appearance color was aqua,and It had the following chemical composition $\mathrm{SiO} 2(66.45 \%)$, $\mathrm{Ai}_{2} \mathrm{O}_{3}(12.3 \%), \mathrm{Fe}_{2} \mathrm{O}_{3}(1.49 \%), \mathrm{TiO}_{2}(0.19 \%), \mathrm{CaO}(3.97 \%)$, $\mathrm{MgO}(0.92 \%), \mathrm{K}_{2} \mathrm{O}(1.54 \%), \mathrm{Na}_{2} \mathrm{O}(1.02 \%), \operatorname{LOS}(12.10 \%)$. The natural zeolite was first milled using grinding bowl and then sifted with 140 meshes. The natural zeolite must preserve in a drying vessel, because it can absorb the water in air.

A cationic polyacrylamide (FC-205), with amolecular weight of $40 \times 10^{5}$ and a aqueous solution viscosity of 800 1500 , was used as a sludge conditioner. The CPAM solutions $(2000 \mathrm{mg} / \mathrm{l})$ were prepared by completely dissolving the powdered polyacrylamide in distilled water. The ferric chloride solutions $(50 \mathrm{~g} / \mathrm{L})$ were prepared by completely dissolving in distilled water as well.

\section{$B$. \\ Experimental Procedure}

Natural zeolite was firstly added to a $100 \mathrm{ml}$ sludge sample in a $200 \mathrm{ml}$ beaker with the different dose which expressed as the percentage of sludge solids concentration. After 30 seconds of rapid mixing (300rpm) at to ensure dispersion, $10 \mathrm{~mL}$ CPAM solutions or $2 \mathrm{~mL}$ ferric chloride solutions were added to the beaker. To promote flocculation, the stirring speed for sludge flocculation is $300 \mathrm{rpm}$ for the first $20 \mathrm{~s}$, followed by $100 \mathrm{rpm}$ for a further $40 \mathrm{~s}$. The contents are then transferred to a funnel fitted with a filter paper and vacuum filtration is started after the contents standing for 1 minute with a vacuum pressure of $0.5 \mathrm{Mpa}$. The vacuum filtration kept working until the vacuum degree was broke, if not, kept working for 10 minutes.

In order to measure the moisture content (MC) of the cakes, the filtrated cakes were dried in an oven at $105^{\circ} \mathrm{C}$ for $4-6 \mathrm{~h}$ until the weight of cakes were constant.

C.

Analytical Methods

Sludge dewater ability was measured by the standard Buchner funnel test and was expressed in terms of the specific resistance to filtration (SRF) and the moisture content (MC) of the cakes.

$$
S R F=\frac{2 P A^{2} a}{\mu \omega} .
$$

The SRF was obtained using the equation (1)[1].

In the equation, $\mu$ is the liquid viscosity ( $\mathrm{Pa} \mathrm{s}$ ), $\mathrm{A}$ is the filter area (m2), $\mathrm{P}$ is the applied pressure (Pa), $\omega$ is the mass of cake solids deposited per volume of filtrate $\left(\mathrm{kg} / \mathrm{m}^{3}\right)$, a is the slope of the linear plot of $t / v$ versus $v$.

The moisture content was measured in accordance with standard ethods[22]. The $\mathrm{pH}$ was measured using a digital $\mathrm{pH}$-meter.

The parameter $\mathrm{c}$ was obtained using the equation (2)

$$
C=\frac{1}{\frac{100-c_{i}}{c_{i}}-\frac{100-c_{f}}{c_{f}}} .
$$

In the equation, $c_{i}$ is the mass of dry sludge of $100 \mathrm{~g}$ sludge; $\mathrm{c}_{\mathrm{f}}$ is the mass of dry sludge of sludge cake.

The concentration of nitrogen was measured use Nessler's reagent spectrophotometry. The ammonia nitrogen concentration of the standard curve was the equation (3)

$$
\mathrm{Y}=0.038 \mathrm{x}-0.008
$$

In this equation, $\mathrm{x}$ is the concentration of ammonia nitrogen $(\mathrm{mg} / \mathrm{L})$; $\mathrm{y}$ is the absorbance.

\section{Results AND Discussions}

\section{A. Dewatering Charrcterristics of CPAM- natural Zeolite Co-conditioned Sludge}

Y.Q. Zhao [11] has demonstrated that addition of skeleton builder but itself could hardly improve dewatering process, because skeleton builder is not a flocculant, it does not have the ability to flocculate the sludge particles as is the case of the polymer, it must in association with a polymer.So this work used CPAM and natural zeolite to cocondition the sludge. It was found that the moisture content (MC) of the cakes decreased with the increase of the natural zeolite dosage, as the dosage of the natural zeolite (>140meshes) from $0 \%$ to $240 \%$, the moisture content (MC) of the cakes from $86.04 \%$ to $82.17 \%$. Similarly, the SRF also decreased, with a natural zeolite dosage of $240 \%$ the sludge SRF decreased 29.4\%.

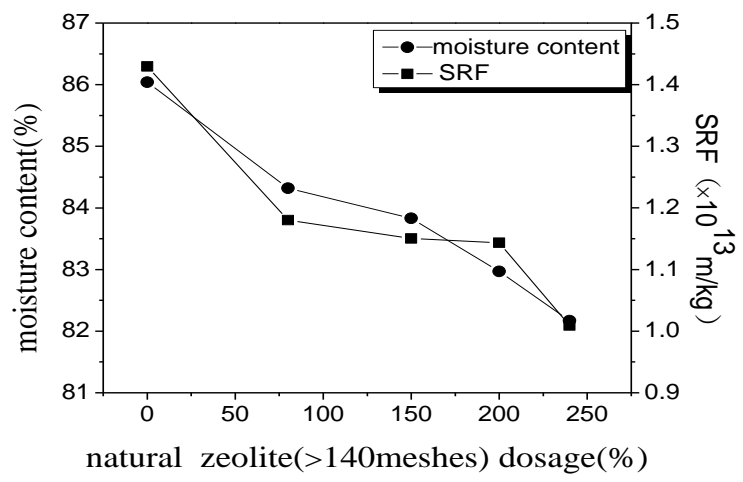

Figure 1. Natural zeolite(>140meshes) and CPAM co-condition the sludge 


\section{B. Dewatering Charrcterristics of Ferric chloride - natural Zeolite Co-conditioned Sludge}

Using natural zeolite associated with ferric chloride solution to co-condition the sludge. As showed in the Fig. 2, the sludge SRF dramatically decreased with the increase of the natural zeolite dosage, nevertheless, when the dosage beyond $80 \%$, the moisture content (MC) of the cakes increased as the natural zeolite dosage increased and some moisture content (MC) of the cakes even higher than that of the sludge which only conditioned with ferric chloride solution. This was no difficulty in explaining the characteristics of ferric chloride was different with that of CPAM. When using ferric chloride and natural zeolite to cocondition the sludge, the sludge cake was cracked and the more dosage of natural zeolite, the more of the cracks. Moreover, the dewater ability would be worse.

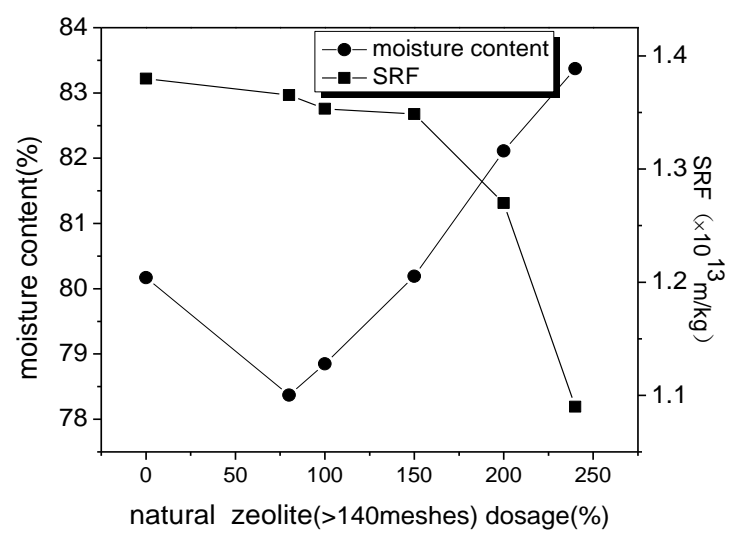

Figure 2. Natural zeolite(>140meshes)and ferric chloride co-condition the sludge

\section{C. $\quad$ The Influence of Natural Zeolite on} Ammonia Nitrogen in the Filtrate of Sludge Dewatering

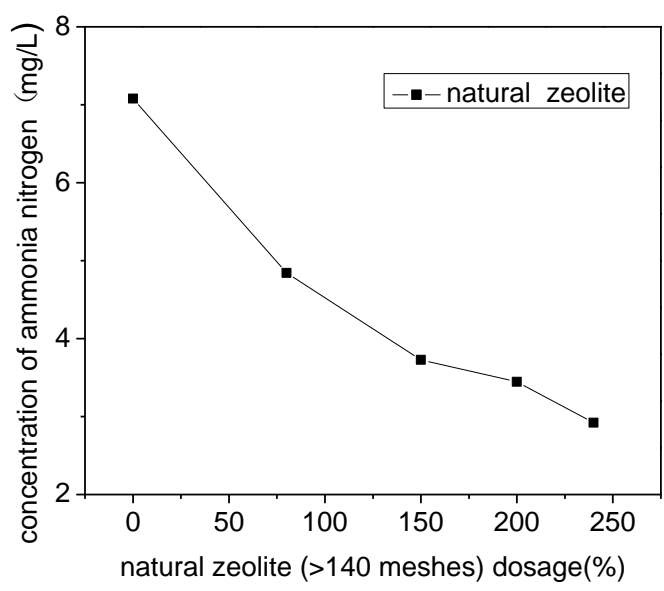

Figure 3. The influence of natural zeolite on ammonia nitrogen in the filtrate

Fig. 3, clearly showed that adding natural zeolite into the sludge could decrease the concentration of ammonia nitrogen in the filtrate, stop ammonia nitrogen to lose. At the dosage of $240 \%$, the concentration of ammonia nitrogen decreased 59\% in the filtrate. Natural zeolite may retain the loss of the nitrogen nutrient in sewage sludge after dehydration and improve agricultural potential of the sludge. In China, most of municipal wastewater treatment plant adopt the method of recirculating sludge water to the influent inlet, which causes the actual nitrogen load of the treatment system higher than the design load, so that there is an incomplete nitrification in municipal wastewater treatment plant [23].So adding natural zeolite into the sludge may offer a selectable way to solve this problem and reduce the risks of water eutrophication.

\section{CONCLUSIONS}

The effects of natural zeolite associatede with CPAM or ferric chloride on sludge dewatering were experimentally measured in this research. It demonstrated that the natural zeolite particals can be used as skeletal builder in sludge condition to improve its filterability. Natural zeolite helps to build up a more porous, permeable and rigid lattice structure of sludge cake. Adding natural zeolite into the sludge could decrease the concentration of ammonia nitrogen in the filtrate, stop ammonia nitrogen losing in sludge, so it can improve the mass of the nitrogen nutrient in sewage sludge after dehydration and improve agricultural potential of the sludge. Moreover, adding natural zeolite into the sludge could solve the problem of the actual nitrogen load of the treatment system higher than the design load, and it could reduce the risks of water eutrophication.

\section{ACKNOWLEDGMENT}

Financial support for this research was provided by the Scientific Research Starting Foundation for Returned Overseas Chinese Scholars, Ministry of Education, China (Grant No. 1061-51200312), the Fundamental Research Funds for the Central Universities, China (Grant No. B11020157). Water Conservancy Research Funds, Jiangsu (1061-51146012). Nantong S\&T Planed Project funds, Jiangsu, Water Conservancy Research Funds, Jiangsu (1061-5126312).

\section{REFERENCES}

[1] Qi, Y., K.B. Thapa and A.F. Hoadley, Application of filtration aids for improving sludge dewatering properties-A review. Chemical Engineering Journal, 2011. 171(2): p. 373-384.

[2] Ning, X., et al., Effects of tannery sludge incineration slag pretreatment on sludge dewaterability. Chemical Engineering Journal, 2013.

[3] Thapa, K.B., et al., Lignite aided dewatering of digested sewage sludge. Water research, 2009. 43(3): p. 623-634.

[4] Thapa, K.B., Y. Qi and A. Hoadley, Interaction of polyelectrolyte with digested sewage sludge and lignite in sludge dewatering. Colloids and Surfaces A: Physicochemical and Engineering Aspects, 2009. 334(1): p. 66-73.

[5] Albertson, O.E. and M. Kopper, Fine-coal-aided centrifugal dewatering of waste activated sludge. Journal (Water Pollution Control Federation), 1983: p. 145-156. 
[6] Sander, B., H. Lauer and M. Neuwirth, Process for producing combustible sewage sludge filter cakes in filter presses. 1989, Google Patents.

[7] Sørensen, P.B. and J.A. Hansen, Extreme solid compressibility in biological sludge dewatering. Water Science \& Technology, 1993. 28(1): p. 133-143.

[8] Lin, Y., S. Jing and D. Lee, Recycling of wood chips and wheat dregs for sludge processing. Bioresource technology, 2001. 76(2): p. 161163.

[9] Zhao, Y.Q., Involvement of gypsum (CaSO4. 2H2O) in water treatment sludge dewatering: a potential benefit in disposal and reuse. Separation science and technology, 2006. 41(12): p. 2785-2794.

[10] Zhao, Y.Q. and D.H. Bache, Conditioning of alum sludge with polymer and gypsum. Colloids and Surfaces A: Physicochemical and Engineering Aspects, 2001. 194(1): p. 213-220.

[11] Zhao, Y.Q., Enhancement of alum sludge dewatering capacity by using gypsum as skeleton builder. Colloids and Surfaces A: Physicochemical and Engineering Aspects, 2002. 211(2): p. 205-212.

[12] Nelson, R.F. and B.D. Brattlof, Sludge pressure filtration with fly ash addition. Journal (Water Pollution Control Federation), 1979: p. 1024-1031.

[13] Chen, C., et al., Sewage sludge conditioning with coal fly ash modified by sulfuric acid. Chemical Engineering Journal, 2010. 158(3): p. 616-622.

[14] Benítez, J., A. Rodriguez and A. Suárez, Optimization technique for sewage sludge conditioning with polymer and skeleton builders. Water Research, 1994. 28(10): p. 2067-2073.
[15] Williams, K.A. and P.V. Nelson, Using precharged zeolite as a source of potassium and phosphate in a soilless container medium during potted chrysanthemum production. Journal of the American Society for Horticultural Science, 1997. 122(5): p. 703-708.

[16] Kasuga, K., et al., Photoactivity of cationic phthalocyanine derivative of zinc (II)-loaded natural zeolites. Inorganic Chemistry Communications, 2003. 6(6): p. 623-625.

[17] Chung, Y., D. Son and D. Ahn, Nitrogen and organics removal from industrial wastewater usingnatural zeolite media. Water Science \& Technology, 2000. 42(5-6): p. 127-134.

[18] Ouki, S.K. and M. Kavannagh, Performance of natural zeolites for the treatment of mixed metal-contaminated effluents. Waste Management \& Research, 1997. 15(4): p. 383-394.

[19] Bosso, S.T. and J. Enzweiler, Evaluation of heavy metal removal from aqueous solution onto scolecite. Water Research, 2002. 36(19): p. $4795-4800$.

[20] Siriwardane, R.V., M. Shen and E.P. Fisher, Adsorption of CO2, N2, and O2 on Natural Zeolites. Energy \& fuels, 2003. 17(3): p. 571-576.

[21] Nojima, S., K. Iida and N. Kobayashi, Selective Reduction of NO X over Iridium Catalyst Supported on MFI-type Metallosilicate for Lean Burn Gasoline Engine. Nippon Kagaku Kaishi, 2001(1): p. 27-36.

[22] Association, A.P.H., W.P.C. Federation and W.E. Federation, Standard methods for the examination of water and wastewater. Vol. 2. 1915: American Public Health Association.

[23] YU Li-fang, PENG Dang-cong, Application and Progress of Nitrogen Removal Technology from Sludge Water in MWW TP. CHINA WATER \& WASTEWATER, 2007. 23(8): p 9-13. 